\title{
Microsatellite analysis of genetic diversity in the squid Illex argentinus during a period of intensive fishing
}

\author{
Greg J. Adcock ${ }^{1, *}$, Paul W. Shaw ${ }^{1}$, Paul G. Rodhouse ${ }^{2}$, Gary R. Carvalho ${ }^{1}$ \\ ${ }^{1}$ Molecular Ecology and Fisheries Genetics Laboratory, Department of Biological Sciences, University of Hull, \\ Hull HU6 7RX, United Kingdom \\ ${ }^{2}$ British Antarctic Survey, Natural Environment Research Council, High Cross, Madingley Rd, Cambridge CB3 OET, \\ United Kingdom
}

\begin{abstract}
Levels of genetic diversity and population differentiation were examined in temporally (1990 to 1997) and geographically separated samples of the argentine short-finned squid Illex argentinus using 7 microsatellite loci. Number of alleles (mean number of alleles per locus over all samples = 24.1 ) and heterozygosity (mean observed heterozygosity per sample $=0.84$ ) were high for all samples, indicating that these loci have a greater potential utility for investigating population genetic structure than allozyme markers used in previous studies. Genetic diversity did not differ significantly between samples taken $5 \mathrm{yr}$ after commencement of the fishery (1990) and those collected during a period of progressively intense fishing pressure (1994 and 1997). Several small but significant differences in between-sample genetic variation $\left(F_{\mathrm{ST}}\right)$ were observed, but these could not confirm the previous suggestion of cryptic species or several well-defined stocks within the fished population.
\end{abstract}

KEY WORDS: Microsatellite - Genetic diversity - Illex argentinus - Squid Population genetics · Fishing

\section{INTRODUCTION}

Rapid fluctuations in population size and incompletely understood stock structure in a migratory species subjected to intensive fishing pressure are likely to complicate effective stock assessment (Hilborn \& Walters 1992, Carvalho \& Nigmatullin 1998). In particular, the impacts of fisheries upon genetic composition of squid populations cannot be adequately predicted from models based on fin-fisheries (Forsythe \& Hanlon 1989). Recent suggestions that even large populations of marine species may lose appreciable allelic diversity during modest population declines (Ryman et al. 1995) underlines the need to monitor harvesting impacts and develop measures for genetic conservation.

The fishery for lllex argentinus (Castellanos 1960) is one of the largest and economically most important for any cephalopod in the world, with recorded annual

-E-mail: g.j.adcock@biosci.hull.ac.uk catches of up to $330000 \mathrm{t}$ (Haimovici et al. 1998). Adult squid, largely from the winter-spawning, South Patagonic stock, are caught mainly between February and June on their main feeding grounds on the southern Patagonian Shelf to the north and west of the Falkland Islands (Fig. 1). Prior to 1980, fishing effort was very low but increased rapidly in the mid-1980s, and in response to this increase the Falkland Islands Government established the Falkland Islands Interim Conservation and Management Zone (FICZ). Since 1992, Argentina has licensed fishing in waters adjacent to the FICZ, which targets the same feeding aggregations, resulting in large increases in annual catch. Although the total catch is currently below the estimated annual harvestable biomass of 600000 to 3 million $t$ (Haimovici et al. 1998), the biomass of adults surviving to spawn is estimated to have been between 26000 and $66000 \mathrm{t}$ during the period 1987 and 1991 , representing annual escapements of 8.7 to $32.1 \%$ (Basson et al. 1996). 


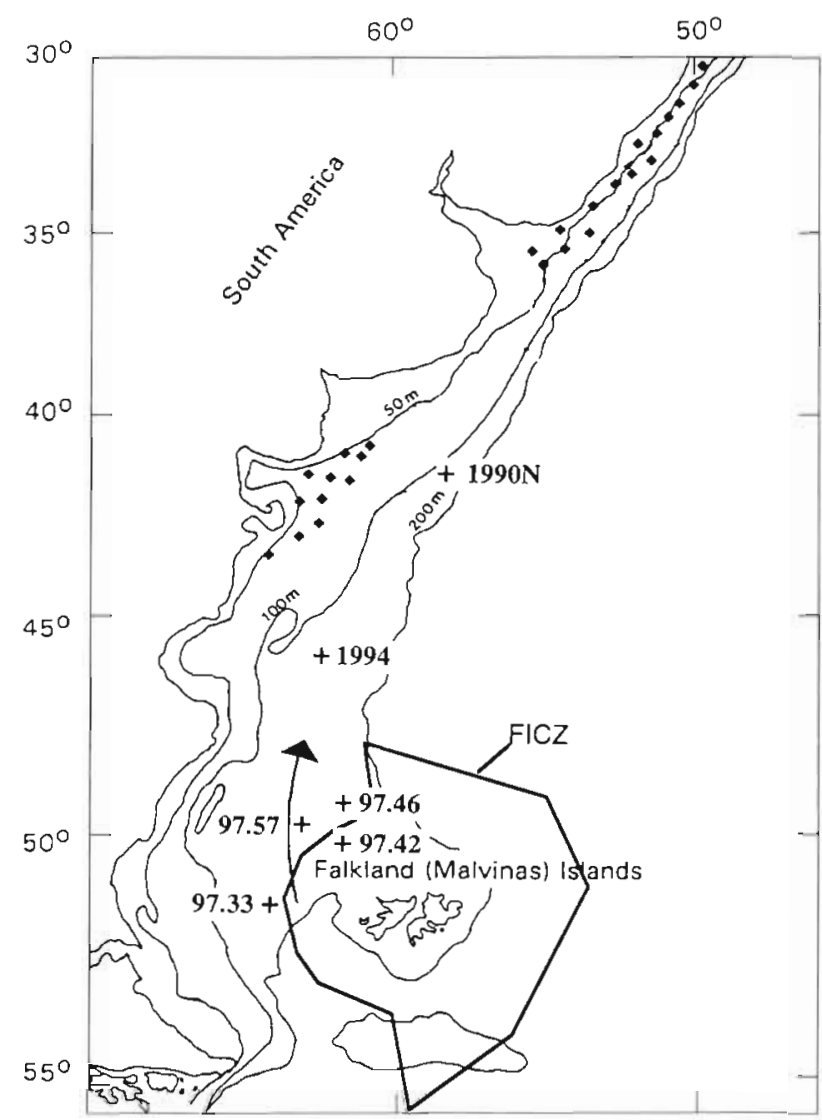

Fig. 1. Map of the Southwest Atlantic showing the extent of the main summer and winter spawning sites (diamonds) of Illex argentinus, the route of their main autumn feeding migration (arrow), and the boundary of the Falkland. Islands Interim Conservation and Management Zone (FICZ). Sample collection sites used in this study $(+)$ include the sample name and day/month of collection. The 1990 sample (not shown) was collected from different sites all within or near the FICZ

The life span of Illex argentinus is 1 yr (Hatanaka 1986, Rodhouse \& Hatfield 1990). The winter-spawning, South Patagonic stock spawns in the vicinity of the confluence of the Brazil and Falkland (Malvinas) Currents. Although the precise location of spawning has not been identified, the greatest concentrations of newly hatched rhynchoteuthion larvae have been found near the shelf break off southern Brazil and Uruguay (Carvalho \& Nigmatullin 1998, Haimovici et al. 1998). Juvenile squid spread southwards over the Patagonian Shelf in spring (Hatanaka 1988) and a return migration northwards is made in autumn (Arkhipkin 1993). Detailed information on population structuring, dynamics and even the accurate definition of taxa has, however, been hampered by the logistical difficulties inherent in studying oceanic species and applying morphological criteria to cephalopods (Pierce et al, 1994, Carvalho \& Nigmatullin 1998). Genetic markers have offered a solution to some of these problems.
Previous studies using allozymes to assess stock structure in Illex argentinus demonstrated low levels of genetic variability (mean heterozygosity per locus = 0.011, Carvalho et al. 1992), and the possible existence of discrete stocks or cryptic species (Thorpe et al. 1986, Carvalho \& Nigmatullin 1998). DNA sequencing studies suggest that mitochondrial DNA (mtDNA) variation is also low (P. W. Shaw unpubl. data). It remains unclear whether the very low levels of polymorphism reported for $I$. argentinus are representative indicators of genomic diversity, or whether such patterns reflect limitations of the tool employed. For example, microsatellite DNA markers exhibit high levels of genetic variation in the squid Loligo forbesi, in contrast to allozyme and mtDNA studies which uncovered very little variability (Shaw et al. 1999)

Microsatellites are rapidly mutating nuclear DNA regions consisting of 1 to 6 base-pair DNA sequences that are tandemly-repeated, generally 6 or more times (Queller et al. 1993). In population and evolutionary genetics studies, microsatellite loci have been shown to be valuable markers for characterization of distinct taxa, population structure and levels of diversity within species (O'Connell \& Wright 1997, Estoup \& Angers 1998). In squid, microsatellites are easy to isolate and highly polymorphic (Shaw 1997, Adcock et al. 1999), and in the one published population study to date (Shaw et al. 1999) microsatellite loci not only confirmed previously observed genetic differentiation, but also identified further population structuring.

In this paper we describe the first application of microsatellites to examine the population genetics of Illex argentinus. We provide an assessment of the characteristics and utility of microsatellites for examining genetic diversity in temporally $(1990,1994$, 1997 ) and spatially (1997) distinct samples. We address the question of whether genetic variability has changed in the exploited population during a period when the catch of migrating individuals has increased substantially.

\section{MATERIALS AND METHODS}

Samples. Localities and dates of sample collection are shown in Fig. 1. The 1990 sample consisted of boxed whole squid that were frozen $\left(-20^{\circ} \mathrm{C}\right)$ on board a commercial vessel within or near the $\mathrm{FICZ}\left(48^{\circ}\right.$ to $52^{\circ} \mathrm{S}, 60^{\circ}$ to $64^{\circ} \mathrm{W}$ ). Twelve individuals (frozen) from a northern locality collected in 1990 (1990n) were samples remaining from a previous analysis of allozyme loci (Carvalho et al. 1992), which identified individuals as representing a separate stock or cryptic species. The 1994 sample consisted of whole frozen squid collected as part of the Russian sponsored 'Atlantida' cruise of 
that year. The 1997 samples were collected by fisheries observers who cut arm tips and placed them immediately into $95 \%$ ethanol on board squid fishing boats. Each of the 1997 samples consisted of individuals from a single haul caught at the same depth and time 197.33 on 13 May 1997, 97.42 on 24 March 1997, 97.46 on 1 March 1997, 97.57 on 14 May 1997).

DNA extraction. DNA was extracted from frozen and ethanol-preserved tissue using the salting-out method of Bruford et al. (1992) with minor refinements. Tissue of less than $50 \mu \mathrm{l}$ in volume was cut from arm tips or mantle and placed into $1.5 \mathrm{ml}$ microfuge tubes containing $300 \mu \mathrm{l}$ of extraction buffer. Precipitated DNA was dissolved in 50 to $100 \mu$ of TE. The observed pink coloration which originated from epidermal chromophores co-purified with the DNA, but did not have any apparent effects on subsequent reactions.

Microsatellite amplification and detection. Microsatellite loci specific for Illex argentinus were chosen from those previously isolated and characterized by Adcock et al. (1999): la112 (TG and GA repeats), la121a (AAT), Ia121b (AAT), Ia201 (CTTT), Ia203 (AAG), Ia207 (AAG) and Ia422 (CT). Ia $121 \mathrm{a}$ and la $121 \mathrm{~b}$ were isolated in a single clone, were separated by 150 base pairs and are presumed to be physically linked. Each of these loci, including the linkage of Ia121a and la121b, were present and polymorphic in other Illex species, $I$. illecebrosus and $I$. coindetti, and therefore each locus predates speciation of $I$. argentinus, and consequently would be expected to amplify equally in cryptic species of $I$. argentinus. Primer sequences, amplification conditions and measurement of PCR product length were performed as described in Adcock et al. (1999). Briefly, all PCR reactions were performed in $10 \mu \mathrm{l}$ volumes using 0.1 units Taq polymerase (Bioline), $1 \times \mathrm{NH}_{4}$ buffer (Bioline), $2.5 \mathrm{mM} \mathrm{MgCl}$, $200 \mathrm{nM}$ dNTPs, 2 pmol each primer (1 primer labeled with Cy5) and 1 to $20 \mathrm{ng}$ genomic DNA, and run for 35 cycles of $94^{\circ} \mathrm{C}$ for $10 \mathrm{~s}$, $55^{\circ} \mathrm{C}$ for $25 \mathrm{~s}$ and $73^{\circ} \mathrm{C}$ for $50 \mathrm{~s}$. Products were run on an ALFexpress ${ }^{\mathrm{TM}}$ automated sequencer (PharmaciaAmersham) together with internal size markers (van Oppen et al. 1997), and sizes scored using the software 'Fragment Manager' (Pharmacia).

Population diversity estimation. Expected heterozygosity $\left(H_{e}\right)$ was calculated assuming Hardy-Weinberg equilibrium $(\mathrm{H}-\mathrm{W})$. Sample heterozygosities were tested for significant differences using Bartlett's measure of heteroscedasticity, and variance heterogeneity between populations was calculated using WINAMOVA v1.5 (Excoffier 1993).

Numbers of alleles were compared among samples by standardizing sample size for each locus. From each population, a random sample of alleles $(2 \mathrm{~N})$ was taken where $\mathrm{N}$ equals the size of the smallest sample for a particular locus. A total of 500 replicates was used to calculate the average, range and $95 \%$ confidence limits for allele numbers for each locus and population. To determine if a population had numbers of alleles that differed significantly from expectations, each locus was resampled $(\times 500)$ from the whole data set using $N$ equal to the sample size being compared. Observed values above or below the $95 \%$ confidence limit of the resampled populations were scored as being significantly different from expected.

An analysis and detailed discussion of the measurement of the diversity of the linked loci, 121a and 121b, are to be published elsewhere. The numbers of linked haplotypes were calculated using the maximum likelihood (ML) approach in the computer program ARLEQUIN v1.1 (Schneider et al. 1997) for data with an unknown gametic phase. This approach estimates the number and composition of haplotypes (i.e. linked alleles at each locus) that best describes all observed diploid genotypes. Maximum parsimony (MP) trees were constructed from the ML data set to estimate numbers of observed alleles derived from more than 1 separate mutation.

Population structure and differentiation. Genotypic data of samples were examined for conformity with Hardy-Weinberg expectations, observed and expected heterozygosity, allele distribution within samples, and linkage disequilibrium among loci within samples using algorithms contained in GENEPOP v3.1 (Raymond \& Rousset 1995).

Estimates of overall genetic divergence among samples were determined using 3 methods, each tested for significance using the Markov chain procedure contained within the respective software. Allele frequency differentiation between pairs of samples was tested using the 'genic differentiation' (Fisher's exact test) option of GENEPOP v3.1 (Raymond \& Rousset 1995). Divergence apportioned among samples, $F_{S T}$, was estimated from theta (Weir \& Cockerham 1984) using FSTAT 1.2 (Goudet 1996). $R_{\mathrm{ST}}$, a measure of population divergence that assumes a stepwise mutation model of microsatellite evolution, was calculated using RSTCALC (Goodman 1997), which adjusts for sample and allele size variance among loci.

\section{RESULTS}

\section{Genetic diversity of Illex argentinus}

Levels of genetic variability within 7 samples of IIlex argentinus were estimated by number of alleles $(A)$ at 7 microsatellite loci (Table 1) and by observed $\left(H_{0}\right)$ and expected $\left(H_{e}\right)$ heterozygosity (Table 2 ). Full details of genotype and allele frequencies are available from the authors on request. 
Table 1. Illex argentinus. Microsatellite allelic diversity. Shown are numbers of alleles $(A)$ for each sample $(N)$ and resampled number of alleles $\left(A_{x}\right.$, where $x$ is sample size), number of linked haplotypes (Ia121ab) resolved using maximum likelihood methods (see 'Materials and methods') and the predicted number of alleles for Ia 121a and Ia121b ( $A_{\mathrm{MP}}$ ) estimated using maximum parsimony. Calculation of probabilities of significant deviations for numbers of alleles is described in the text, where ' $\uparrow$ ' indicates the number of alleles greater than $95 \%$ confidence limits $(\mathrm{p}<0.05)$ and ' $\downarrow$ ' indicates those less than $95 \%$ confidence limits $(p<0.05)$. Significance of all mean values was calculated using combined probabilities (Manly 1985) of each locus or sample as appropriate

\begin{tabular}{|c|c|c|c|c|c|c|c|c|c|c|}
\hline Locus & & $1990 n$ & 1990 & 1994 & 97.33 & 97.42 & 97.46 & 97.57 & 1997 & All \\
\hline Ia112 & $\begin{array}{l}A(N) \\
A_{12}\end{array}$ & $\begin{array}{c}9(12) \\
9\end{array}$ & $\begin{array}{c}16(52) \\
10.9\end{array}$ & $\begin{array}{c}18(35) \\
11.7\end{array}$ & $\begin{array}{c}18(36) \\
11.7\end{array}$ & $\begin{array}{c}14(40) \\
10.8\end{array}$ & $\begin{array}{c}19(39) \\
11.7\end{array}$ & $\begin{array}{c}15(35) \\
9.8\end{array}$ & $\begin{array}{c}24(150) \\
11.2\end{array}$ & $\begin{array}{c}26(249) \\
11.1\end{array}$ \\
\hline Ia $121 \mathrm{a}$ & $\begin{array}{l}A(N) \\
A_{M P}(N) \\
A_{12}\end{array}$ & $\begin{array}{c}15(12) \\
15(12) \\
15\end{array}$ & $\begin{array}{c}33(66) \\
25(27) \\
17.1\end{array}$ & $\begin{array}{c}25(38) \\
31(36) \\
16.5\end{array}$ & $\begin{array}{c}26(38) \\
31(37) \\
15.1\end{array}$ & $\begin{array}{c}27(40) \\
32(40) \\
15.9\end{array}$ & $\begin{array}{c}30(38) \\
32(38) \\
16.4\end{array}$ & $\begin{array}{c}29(37) \\
31(36) \\
16.4\end{array}$ & $\begin{array}{c}38(153) \\
- \\
16.3\end{array}$ & $\begin{array}{c}38(269) \\
- \\
16.4\end{array}$ \\
\hline Ia121b & $\begin{array}{l}A(N) \\
A_{M P}(N) \\
A_{12}\end{array}$ & $\begin{array}{c}17(12) \\
17(12) \\
17\end{array}$ & $\begin{array}{c}30(27) \\
31(27) \\
18.0 \uparrow\end{array}$ & $\begin{array}{c}31(38) \\
32(36) \\
16.7\end{array}$ & $\begin{array}{c}29(39) \\
30(37) \\
16.4\end{array}$ & $\begin{array}{c}27(40) \\
33(40) \\
14.4\end{array}$ & $\begin{array}{c}26(39) \\
37(38) \\
14.9\end{array}$ & $\begin{array}{c}23(39) \\
26(36) \\
13.8 \downarrow\end{array}$ & $\begin{array}{c}44(157) \\
- \\
14.9\end{array}$ & $\begin{array}{c}44(234) \\
- \\
15.4\end{array}$ \\
\hline Ia $121 \mathrm{ab}$ & & 22 & 48 & 60 & 59 & 63 & 67 & 55 & 194 & 260 \\
\hline $\mathrm{Ia} 201$ & $\begin{array}{l}A(N) \\
A_{12}\end{array}$ & $\begin{array}{c}4(12) \\
4\end{array}$ & $\begin{array}{l}6(66) \\
3.6\end{array}$ & $\begin{array}{c}6(38) \\
4.6\end{array}$ & $\begin{array}{c}7(36) \\
4.8\end{array}$ & $\begin{array}{l}6(40) \\
3.8\end{array}$ & $\begin{array}{l}6(39) \\
4.5\end{array}$ & $\begin{array}{l}6(35) \\
4.0\end{array}$ & $\begin{array}{c}7(150) \\
4.3\end{array}$ & $\begin{array}{c}7(266) \\
4.1\end{array}$ \\
\hline $\mathrm{Ia} 203$ & $\begin{array}{l}A(N) \\
A_{12}\end{array}$ & $\begin{array}{c}11(12) \\
11\end{array}$ & $\begin{array}{c}14(51) \\
10.4\end{array}$ & $\begin{array}{c}12(39) \\
9.9\end{array}$ & $\begin{array}{c}14(38) \\
10.2\end{array}$ & $\begin{array}{c}13(40) \\
9.3\end{array}$ & $\begin{array}{c}12(36) \\
10.1\end{array}$ & $\begin{array}{c}14(39) \\
9.7\end{array}$ & $\begin{array}{c}17(153) \\
10.0\end{array}$ & $\begin{array}{c}18(254) \\
10.2\end{array}$ \\
\hline Ia207 & $\begin{array}{l}A(N) \\
A_{11}\end{array}$ & $\begin{array}{c}8(11) \\
8\end{array}$ & $\begin{array}{c}15(60) \\
10.0\end{array}$ & $\begin{array}{c}14(38) \\
9.5\end{array}$ & $\begin{array}{c}16(40) \\
9.9\end{array}$ & $\begin{array}{c}14(39) \\
9.6\end{array}$ & $\begin{array}{c}16(39) \\
9.7\end{array}$ & $\begin{array}{c}14(38) \\
9.7\end{array}$ & $\begin{array}{c}20(156) \\
9.8\end{array}$ & $\begin{array}{c}23(265) \\
9.8\end{array}$ \\
\hline 12422 & $\begin{array}{l}A(N) \\
A_{12}\end{array}$ & $\begin{array}{c}6(12) \\
6\end{array}$ & $\begin{array}{c}7(58) \\
4.5\end{array}$ & $\begin{array}{l}9(40) \\
6.4\end{array}$ & $\begin{array}{l}8(31) \\
5.5\end{array}$ & $\begin{array}{c}8(37) \\
4.6\end{array}$ & $\begin{array}{l}6(38) \\
3.9\end{array}$ & $\begin{array}{l}6(39) \\
3.9\end{array}$ & $\begin{array}{c}11(145) \\
4.8\end{array}$ & $\begin{array}{c}13(255) \\
5.1\end{array}$ \\
\hline All loci & $\begin{array}{l}\text { Mean } A \\
\text { Mean } A_{i}\end{array}$ & $\begin{array}{l}10.0 \\
10.0\end{array}$ & $\begin{array}{l}17.2 \\
10.6\end{array}$ & $\begin{array}{l}16.4 \\
10.8\end{array}$ & $\begin{array}{l}16.8 \\
10.5\end{array}$ & $\begin{array}{c}15.6 \\
9.8\end{array}$ & $\begin{array}{l}16.4 \\
10.3\end{array}$ & $\begin{array}{l}15.3 \\
9.6\end{array}$ & $\begin{array}{l}23.0 \\
10.2\end{array}$ & $\begin{array}{l}24.1 \\
10.3\end{array}$ \\
\hline
\end{tabular}

All loci were highly polymorphic within all samples, with total number of alleles (A) per locus for all samples pooled ranging from 7 to 44 (mean $=24.1$ ). Variation in allelic diversity was observed between samples, but when number of alleles was adjusted for sample size $\left(A_{x}\right.$, Table 1$)$ almost no significant variation was present. Only 2 samples were above or below the $95 \%$ confidence limits of numbers of alleles expected from resampling from all samples pooled: number of alleles for the 1990 sample at locus Ia $121 \mathrm{~b}(\mathrm{p}=0.02)$ was above, and 97.57 at Ia $121 \mathrm{~b}(\mathrm{p}=0.02)$ below (Table 1$)$. Comparisons between samples from different years (1990, 1994 and 1997 pooled) indicated no significant differences in number of alleles, either within or across all loci.

Mean observed heterozygosity (Table 2) was high for all samples $\left(H_{0}=0.76\right.$ to 0.85$)$ and loci $\left(H_{0}=0.59\right.$ to $0.93)$. Gene diversity $\left(H_{e}\right)$ did not differ significantly between samples, within individual loci or across all loci combined, when tested with Bartlett's heteroscedasticity (Excoffier 1993). As with allelic diversity, comparisons between samples from different years (1990, 1994 and 1997 pooled) indicated no significant differences in gene diversity (heterozygosity), either within or across loci.
Reconstruction of the 2-locus haplotypes indicates that the true allelic diversity at Ia121a and Ia121b is probably much higher than the observed number of electrophoretic variants (G. J. Adcock unpubl. data). The number of alleles calculated using MP from ML data sets $\left(A_{M P}\right.$, Table 1$)$ is greater than the observed number of alleles $(A)$ for each sample, with the number identical by descent being possibly greater than 150 per locus. The number of bi-locus haplotypes estimated for each sample (la121ab. Table 1) is also very high (approximately 60 for a sample of 40 individuals, and 260 for the entire data set). This higher than observed number of alleles at Ia121a and Ia121b is not important for temporal comparisons among samples because a significant reduction in effective population size will affect observed numbers of alleles at these loci in the same way as at other loci.

\section{Population structure and differentiation}

No significant evidence of linkage disequilibrium was observed between any of the 7 loci examined. Only 4 out of 142 pair-wise tests were significant at $\mathrm{p}<$ 0.05 (97.42 with loci I121a and I121b, 97.33 with Ia207 
Table 2. Illex argentinus. Observed $\left(H_{0}\right)$ and expected $\left(H_{e}\right)$ heterozygosity at 7 microsatellite loci in 7 samples. Hardy-Weinberg significance was determined using a Markov chain method (Guo \& Thompson 1992), $p<0.05, \cdots p<0.01, \cdots p<0.001$. Significance of all mean values was calculated using combined probabilities (Manly 1985) of each locus or sample as appropriate. Values remaining significant after sequential Bonferroni correction are in bold

\begin{tabular}{|c|c|c|c|c|c|c|c|c|c|c|}
\hline Locus & & $1990 n$ & 1990 & 1994 & 97.33 & 97.42 & 97.46 & 97.57 & 1997 & All \\
\hline \multirow[t]{2}{*}{ Ia 112} & $H_{0}$ & 0.83 & $0.94^{\circ}$ & 0.86 & 0.94 & 0.88 & 0.90 & $0.74 \cdots$ & 0.87 & $0.88^{\circ}$ \\
\hline & $H_{\mathrm{e}}$ & 0.91 & 0.90 & 0.91 & 0.92 & 0.92 & 0.91 & 0.87 & 0.91 & 0.91 \\
\hline \multirow[t]{2}{*}{ Ia121a } & $H_{0}$ & $0.83^{\circ}$ & 0.94 & 0.97 & 0.92 & 0.95 & $0.82^{\circ}$ & 1.00 & 0.92 & $0.93^{\circ}$ \\
\hline & $H_{\mathrm{e}}$ & 0.95 & 0.97 & 0.97 & 0.95 & 0.96 & 0.96 & 0.96 & 0.96 & 0.96 \\
\hline \multirow[t]{2}{*}{ Ia $121 \mathrm{~b}$} & $H_{0}$ & 0.92 & 0.93 & 1.00 & 0.95 & 0.93 & 0.87 & 0.87 & 0.90 & 0.92 \\
\hline & $H_{e}$ & 0.95 & 0.97 & 0.96 & 0.96 & 0.94 & 0.94 & 0.94 & 0.95 & 0.95 \\
\hline \multirow[t]{2}{*}{ Ia201 } & $H_{0}$ & 0.58 & 0.55 & 0.66 & $0.64^{\circ}$ & 0.63 & 0.67 & 0.43 & 0.59 & $0.59^{\circ}$ \\
\hline & $H_{\mathrm{e}}$ & 0.47 & 0.59 & 0.65 & 0.68 & 0.60 & 0.67 & 0.60 & 0.64 & 0.62 \\
\hline \multirow[t]{2}{*}{$\mathrm{Ia} 203$} & $H_{0}$ & 0.92 & 0.90 & 0.92 & 0.87 & 0.98 & 0.81 & $0.72^{\circ}$ & 0.84 & $0.87^{\circ}$ \\
\hline & $H_{\mathrm{e}}$ & 0.92 & 0.91 & 0.90 & 0.88 & 0.89 & 0.91 & 0.89 & 0.90 & 0.90 \\
\hline \multirow[t]{2}{*}{$\mathrm{Ia} 207$} & $H_{0}$ & 0.91 & 0.83 & 0.92 & 0.95 & 0.92 & 0.79 & 0.92 & 0.90 & 0.89 \\
\hline & $H_{\mathrm{e}}$ & 0.83 & 0.89 & 0.83 & 0.88 & 0.89 & 0.86 & 0.89 & 0.88 & 0.88 \\
\hline \multirow[t]{2}{*}{$\operatorname{Ia} 422$} & $H_{0}$ & 0.67 & 0.72 & 0.63 & 0.55 & 0.57 & 0.53 & 0.64 & 0.57 & 0.62 \\
\hline & $H_{\mathrm{e}}$ & 0.63 & 0.64 & 0.71 & 0.65 & 0.63 & 0.66 & 0.60 & 0.64 & 0.66 \\
\hline \multirow{2}{*}{ All loci } & Mean $H_{\mathrm{o}}$ & 0.79 & 0.83 & 0.85 & 0.83 & 0.84 & $0.77^{\circ}$ & $0.76^{\circ}$ & $0.80^{\circ}$ & $0.81^{\circ}$ \\
\hline & Mean $H_{\mathrm{e}}$ & 0.81 & 0.84 & 0.85 & 0.85 & 0.83 & 0.84 & 0.82 & 0.84 & 0.84 \\
\hline
\end{tabular}

and Ia422, $1990 n$ with Ia112 and Ia 121 a, and 1990 with Ia 112 and Ia422), a result consistent with chance Type I error (all become non-significant if adjusted by sequential Bonferroni procedure, Rice 1989). This result includes comparisons between loci la121a and Ia $121 \mathrm{~b}$, which is consistent with the predictions from the ML analysis of a very high number of unique alleles. Comparisons between Ia121a and Ia121 b, other than the significant value for 97.42, had high probabilities ( $>0.8$ ), and were not significant when combined across all comparisons. The allelic variation at all loci will therefore be treated as independent for describing sample differences.

Genotypic distributions at most loci within most samples did not depart significantly from H-W expectations for random outcrossing (Table 2). The few significant results show no apparent locus- or samplespecific pattern, and only la112 within 97.57 and la121a within 97.46 remain significant when adjusted for table-wide significance using the sequential Bonferroni procedure (Rice 1989). These results indicate that null (non-amplifying) alleles and heterozygote scoring (large allele 'drop-out') are not a concern with the loci employed here. Multi-locus tests, using combined probabilities (Manly 1985), indicate that only 2 samples (again 97.46 and 97.57, Table 2) show overall departures from expected genotypic frequencies, both largely due to deficits of heterozygotes at the individual loci noted above.
Exact tests of allele frequencies and estimates of between sample genetic variance $\left(F_{\mathrm{ST}}\right.$ and $R_{\mathrm{ST}}$ ) all indicate significant heterogeneity across all samples combined (Exact $\mathrm{p} \ll 0.001 ; F_{\mathrm{ST}}=0.004, \mathrm{p}<0.001 ; R_{\mathrm{ST}}=$ $0.012, \mathrm{p} \ll 0.001)$. A number of significant departures from homogeneity in allele frequencies (Table 3) and estimates of $F_{\mathrm{ST}}$ and $R_{\mathrm{ST}}$ significantly greater than zero (Table 4) were also found in pair-wise tests between samples. Levels of significance are, however, marginal with few values remaining significant when adjusted for table-wide effects (Rice 1989) - see values in bold in Tables $3 \& 4$. Pair-wise values of $F_{\mathrm{ST}}(0$ to 0.029$)$ and $R_{\mathrm{ST}}(0$ to 0.046$)$ are low and do not appear to indicate any consistent pattern of distinct differences between particular samples, either geographically or temporally. Values of $F_{\text {ST }}$ between $1990 n$ and the rest are higher than average (but non-significant due to the small sample size involved), although $R_{\mathrm{ST}}$ values do not confirm this pattern.

\section{DISCUSSION}

\section{Genetic diversity}

Illex argentinus exhibits very high levels of genetic diversity at the 7 microsatellite loci examined. In the combined sample, mean values of heterozygosity $\left(H_{\mathrm{e}}=\right.$ $0.84)$ and number of alleles $(A=24.1)$ are comparable with the high levels seen in microsatellite studies of 
Table 3. Illex argentinus. Exact tests of microsatellite allelic frequency differences between samples. Shown above the diagonal are multi-locus probabilities of homogeneity (values remaining significant after sequential Bonferroni correction in bold) and below the diagonal are the individual loci exhibiting significant differences $(1$, la 112; 2, Ia 121a; 3, Ia121b; 4, Ia201; 5, Ia203; 6. Ia207; 7, Ia $422 ; p<0.05, \cdots p<0.01, \cdots p<0.001)$

\begin{tabular}{|c|c|c|c|c|c|c|c|c|}
\hline Sample & $1990 n$ & 1990 & 1994 & 97.33 & 97.42 & 97.46 & 97.57 & 1997 \\
\hline $90 n$ & & 0.29 & 0.63 & 0.01 & 0.24 & 0.06 & 0.04 & 0.11 \\
\hline 1990 & $4^{\circ}$ & & 0.16 & 0.34 & 0.27 & 0.44 & 0.17 & 0.49 \\
\hline 1994 & & $7^{\cdot} 1^{\circ}$ & & 0.02 & 0.57 & 0.05 & 0.02 & 0.03 \\
\hline 97.33 & $2 \cdots^{\circ}$ & & $7 \cdots$ & & 0.006 & 0.53 & 0.002 & - \\
\hline 97.42 & $2^{\cdot}$ & & & $2^{\cdot}$ & & 0.02 & 0.007 & - \\
\hline 97.46 & $4^{\cdot} 7^{\circ}$ & & $7 \cdot 1 \cdots$ & & & & 0.01 & - \\
\hline 97.57 & $1 \cdot$ & & $5^{\circ}$ & $3^{\circ} 5^{\circ} 7^{\circ}$ & $1 \cdots 5^{\circ}$ & & & - \\
\hline 97 all & $7^{\circ}$ & & $7 \cdots$ & & & & & \\
\hline
\end{tabular}

Table 4. Illex argentinus. Pair-wise estimates of multi-locus $F_{\mathrm{ST}}$ (above diagonal) and $R_{\mathrm{ST}}$ (below diagonal) between samples, with results of permutation tests showing significant departures from zero ( $\mathrm{p}<0.05, \cdots p<0.01, \cdots p<0.001$; values remaining significant after sequential Bonferroni correction in bold)

\begin{tabular}{|c|c|c|c|c|c|c|c|}
\hline Sample & $1990 n$ & 1990 & 1994 & 97.33 & 97.42 & 97.46 & 97.57 \\
\hline $90 n$ & & $0.017^{\circ}$ & 0.008 & $0.029^{* *}$ & 0.008 & $0.018^{\circ}$ & 0.017 \\
\hline 1990 & 0.004 & & $0.005^{\circ}$ & 0.001 & -0.001 & -0.002 & 0.002 \\
\hline 1994 & 0.014 & $0.024^{*}$ & & $0.011^{\mu}$ & -0.000 & 0.000 & 0.004 \\
\hline 97.33 & 0.0123 & -0.006 & $0.022^{\circ}$ & & $0.006^{\circ}$ & -0.000 & $0.010^{\circ}$ \\
\hline 97.42 & -0.0072 & $0.013^{\circ}$ & 0.015 & 0.014 & & 0.003 & 0.002 \\
\hline 97.46 & 0.002 & $0.016^{\circ}$ & $0.021^{\star}$ & $0.022^{\circ}$ & -0.003 & & 0.002 \\
\hline 97.57 & 0.006 & $0.022^{*}$ & $0.046 " *$ & $0.033^{*}$ & 0.000 & 0.003 & \\
\hline
\end{tabular}

pelagic fish (O'Connell \& Wright 1997, Hauser \& Ward 1998), and the squid Loligo forbesi (mean $H_{e}=0.79$, mean $A=18.2$, Shaw et al. 1999). As shown by the linkage analysis of Ia121a and Ia 121b, the number of alleles observed as discrete PCR product sizes may be an underestimate of true allelic diversity. Homoplasy might be very high therefore, indicating that even larger numbers of alleles are being maintained in the population, although this observation might alternatively indicate that Ia121a and Ia $121 \mathrm{~b}$ are particularly mutable or recombinative. Since the implications of these possibilities are quite different, it will be worthwhile to distinguish between them by sequence analysis of a range of alleles at these loci.

The high levels of microsatellite diversity described here contrast with the low levels of allozymic variation (for the 12 polymorphic loci found among 25 tested, mean $H_{\mathrm{e}}=0.011$ and mean $A=3.5$ ) observed previously in Illex argentinus (Carvalho et al. 1992). The microsatellite data suggest that low allozyme diversity in this species is not explained by a severe population size bottleneck in the recent past, but the data do not rule out selective forces, such as those peculiar to cold water species (Nevo et al. 1984) acting on allozyme diversity. If a more ancient bottleneck occurred, then the difference in allelic diversity between allozyme and micro- satellite loci may be a reflection of widely differing mutation rates. While a recent population crash has probably not occurred, there is at least a potential that the introduction of a fishery might reduce overall levels of diversity. Ryman et al. (1995) suggested that many relatively rare alleles could be lost, even in the large populations typical of many marine species, when population reductions are proportionally small. Microsatellite data presented here indicate that heterozygosity and numbers of alleles are similarly high between 1990 and 1997 despite intensive fishing pressure. As number of alleles is known to be generally more sensitive to population reductions (Ryman et al. 1995), this parameter was examined further using resampling methods. From this, no significant differences in diversity were indicated between 1990 and 1997

The routine monitoring of changes in levels of diversity would require the regular analysis of a large number of samples and large sample sizes. The 7 loci presented here are appropriate for such a study by virtue of their high diversity, and can be supplemented to increase sensitivity by addition of 1 other locus (Ia408, Adcock et al. 1999). The linked loci when combined to form a single highly variable locus, might prove to be more sensitive for detection of reductions in numbers of alleles. 


\section{Stock structure}

No consistent pattern of geographic or temporally based stock structure is apparent using microsatellite markers among the samples examined here. Some degree of genetic heterogeneity is present across the whole sample set, as indicated by allele frequencies and the between-sample component of genetic variation $\left(F_{\mathrm{ST}}\right)$, but pair-wise sample differences are small and not consistent across tests.

Two samples exhibited significant overall departures of genotypic frequencies from outbreeding expectations (97.46 and 97.57). Carvalho et al. (1992) described allozyme frequency differences between samples collected several hours apart, suggesting that individual shoals of squid might be genetically differentiated. Mixing of differentiated shoals within a catch would be expected to produce apparent deficits of heterozygotes, an interesting possible explanation for the pattern seen for 97.46 and 97.57 . The high observed allelic diversity within these samples, however, implies that shoals do not consist of individuals recruited from localized areas containing the progeny of a relatively small number of parents. The fact that all the 1997 samples show high diversity, are not significantly differentiated from one another, and represent squid caught almost simultaneously, suggests that fishing practices are either not selectively harvesting from within particular shoals, or that shoals do not relate to localized founding aggregations.

The general lack of significant genetic heterogeneity among the samples of Illex argentinus considered here contrasts in part with previous allozyme data on this species, which identified low levels of differentiation, apart from the most northern sample which was sufficiently different to merit the suggestion of a cryptic species (Carvalho et al. 1992). Sample 1990n (Fig. 1), which comprises a subset of individuals from the putative cryptic sample of Carvalho et al. (1992), did not appear markedly different from other samples using microsatellites. Owing to their high mutation rate and mutational constraints, microsatellite loci can be limited in their effectiveness in phylogenetic analyses at higher taxonomic levels (Estoup \& Angers 1998). This might explain the lack of differentiation between sample $1990 \mathrm{n}$ and the other samples examined here, although the small sample size $(n=12)$ precludes a rigorous test using frequency data. In comparisons among species and higher taxonomic levels, microsatellites often show shifts in allele sizes and size ranges (Primmer \& Ellegren 1998), as seen with the loci used in the present study when applied to other members of the genus, e.g. I. illecebrosus and I. coindetti (Adcock et al. 1999). Sample 1990n does not show such divergent allele types, which would be detectable even with such a small sample. Ideally though, further taxonomic assessment would be enhanced by a larger sample of any proposed cryptic species and the employment of microsatellite loci which have low mutation rates (less homoplasy) or other informative markers such as mtDNA. The overall geographic genetic homogeneity of $I$. argentinus within the FlCZ indicated by the present study, however, is consistent with the majority of samples examined by the earlier allozyme studies. It appears therefore that $I$. argentinus sampled in the main fishing area within the FICZ to the north and west of the Falkland Islands comprise a single stock, possibly corresponding to the main migratory mass of the Patagonic stock (Fig. 1), and do not therefore include postulated separate in-shore stocks (Carvalho \& Nigmatullin 1998). A more complete study involving sampling from the full geographic range of this species, especially the spawning grounds, will be needed before an accurate picture of relationships between inshore/offshore and postulated separate spawning stocks can be made: the microsatellite loci utilized here would undoubtedly provide reliable genetic markers for such a study, preferably in combination with corroborative data from markers such as allozymes and mtDNA.

In conclusion, the exploited population of Illex argentinus within the FICZ was shown to maintain high levels of microsatellite diversity, and that levels of genetic variability have not changed during almost a decade of intensive fishing pressure. Our data indicate that the stock within the sampled region is probably genetically homogeneous. We suggest that by virtue of their variability, microsatellites represent a potentially powerful tool for investigating other aspects of the population biology of 1 . argentinus such as egg mass composition and relatedness of school members.

Acknowledgements. We are grateful to Conor Nolon (Fisheries Department, Falkland Islands), and Chingis Nigmatullin (AtlantNIRO, Russia) for squid samples, and to Cock van Oosterhout for writing a program using a resampling method for the calculation of numbers of alleles. This work was supported by NERC Grant GR9/2758

\section{LITERATURE CITED}

Adcock GJ, Carvalho GR, Rodhouse PG, Shaw PW (1999) Highly polymorphic microsatellite loci of the heavily fished genus Illex (Ommastrephidae). Mol Ecol 8:165-167

Arkhipkin AI (1993) Age, growth, stock structure and migratory rate of prespawning short-finned squid, Mlex argentinus, based on statolith aging investigations. Fish Res (Amst) 16:313-338

Basson M, Beddington JR, Crombie JA, Holden SJ, Purchase LV, Tingley GA (1996) Assessment and management of annual squid stocks: the Illex argentinus fishery in the Southwest Atlantic as an example. Fish Res (Amst) 28:3-29 
Bruford MW, Hanotte O, Brookfield JFY, Burke T (1992) Single locus and multilocus DNA fingerprinting. In: Hoelzel AR (ed) Molecular genetic analysis of populations-a practical approach. IRL Press, Oxford

Carvalho GR, Nigmatullin CM (1998) Stock structure analysis and species identification. In: Rodhouse PG, Dawe EG, O'Dor RK (eds) Squid recruitment dynamics. The genus Hex as a model, the commercial Illex species and influences on variability. FAO Fisheries Technical Paper No. 376, FAO, Rome, p 199-232

Carvalho GR, Thompson A, Stoner AL (1992) Genetic diversity and population differentiation of the shortfin squid Illex argentinus in the south-west Atlantic. J Exp Mar Biol Ecol 158:105-121

Castellanos ZJA de (1960) Una nueva especie de calamar Argentino Ommastrephes argentinus sp. nov. (Mollusca, Cephalopoda). Neotropica (La Plata) 6:55-58

Estoup A, Angers B (1998) Microsatellites and minisatellites for molecular ecology: theoretical and empirical considerations. In: Carvalho GR (ed) Advances in molecular ecology. NATO Science Series, Vol 306, IOS Press, Amster. dam, p 55-86

Excoffier L (1993) WINAMOVA Ver. 1.5: analysis of molecular variance. Computer program, University of Geneva, Geneva

Forsythe JW, Hanlon RT (1989) Growth in eastern Atlantic squid, Loligo forbesi Steenstrup (Mollusca, Cephalopoda). Aquacult Fish Manag 20:1-14

Goodman SJ (1997) RST CALC: a collection of computer programs for calculating unbiased estimate of genetic differentiation and gene flow from microsatellite data and determining their significance. Mol Ecol 6:881-885

Goudet J (1996) F-STAT (Ver. 1.2), a program for IBM PC compatibles to calculate Weir and Cockerham's (1984) estimators of $F$-statistics. J Hered 86:485-486

Guo SW, Thompson EA (1992) Performing the exact test of Hardy-Weinberg proportions for multiple alleles. Biometrics 48:361-372

Haimovici M, Brunetti NE, Rodhouse PG, Csirke J, Leta RH (1998) Illex argentinus. In: Rodhouse PG, Dawe EG, O'Dor RK (eds) Squid recruitment dynamics. The genus Illex as a model, the commercial Illex species and influences on variability. FAO Fisheries Technical Paper No. 376, FAO, Rome, p 27-58

Hatanaka $H$ (1986) Growth and life span of the short-finned squid, Illex argentinus, in the waters off Argentina. Bull Jpn Soc Sci Fish 52:11-17

Hatanaka H (1988) Feeding migration of short-finned squid Illex argentinus in the waters off Argentina. Nippon Suison Gakkashi 54:1343-1349

Hauser L, Ward RD (1998) Population identffication in pelagic fish: the limits of molecular markers. In: Carvalho GR (ed) Advances in molecular ecology. NATO Science Series Vol 306, IOS Press, Amsterdam, p 191-224

Editorial responsibility: Otto Kinne (Editor), Oldendorf/Luhe, Germany
Hilborn R, Walters CJ (1992) Quantitative fisheries stock assessment: choice, dynamics and uncertainty. Chapman and Hall, New York

Manly BFJ (1985) Statistics of natural selection. Chapman and Hall, London

Nevo E, Beiles A, Ben-Shlomo R (1984) The evolutionary significance of genetic diversity: ecological, demographic and life-history correlates. In: Mani GS (ed) Evolutionary dynamics of genetic diversity. Springer-Verlag, Berlin, p 13-213

O'Connell M, Wright JM (1997) Microsatellite DNA in fishes. Rev Fish Biol Fish 7:331-363

Pierce GJ, Hastie LC, Guerra A, Thorpe RS, Howard FG, Boyle PR (1994) Morphometric variation in Loligo forbesi and Loligo vulgaris: regional, seasonal, maturity and worker differences. Fish Res 21:127-148

Primmer CR, Ellegren $H$ (1998) Patterns of molecular evolution in avian microsatellites. Mol Biol Evol 15: 997-1008

Queller DC, Strassman JE, Hughes CR (1993) Microsatellites and kinship. Trends Ecol Evol 8:285-288

Raymond M, Rousset F (1995) GENEPOP (Ver. 1.2) - population genetics software for exact tests and ecumenicism. J Hered 86:248-249

Rice WR (1989) Analysing tables of statistical tests. Evolution 43:223-225

Rodhouse PG, Hatfield EMC (1990) Dynamics of growth and maturation in the cephalopod Illex argentinus de Castellanos, 1960 (Teuthoidea: Ommastrephidae). Phil Trans R Soc Lond Biol Sci 329:229-241

Ryman N, Utter F, Laikre L (1995) Protection of intraspecific biodiversity of exploited fishes. Rev Fish Biol Fish 5: $417-446$

Schneider S, Kueffer JM, Roessli D, Excoffier L (1997) ARLEQUIN ver. 1.1: a software for population genetic data analysis. Genetics and Biometry Laboratory, University of Geneva, Geneva

Shaw PW (1997) Polymorphic microsatellite DNA markers in the veined squid Loligo forbesi. Mol Ecol 6:297-298

Shaw PW, Pierce G, Boyle PR (1999) Subtle population structuring within a highly vagile marine invertebrate, the veined squid Loligo forbesi (Cephalopoda: Loliginidae) uncovered using microsatellite DNA markers. Mol Ecol 8: $407-417$

Thorpe JP, Havenhand JN, Patterson KR (1986) Report of the University of Liverpool to the Falkland Islands Development Corporation on stock and species identities of Patagonian shelf Illex argentinus. Falkland Islands corporation, Port Stanley, Falkland Islands (unpubl.)

van Oppen MJH, Rico C, Deutsch JC, Turner GF, Hewitt GM (1997) Isolation and characterization of microsatellite loci in the cichlid fish Pseudotropheus zebra. Mol Ecol 6: $387-388$

Weir BS, Cockerham CC (1984) Estimating F-statistics for the analysis of population structure. Evolution 38:1358-1370

Submitted: January 29, 1999; Accepted: May 10, 1999

Proofs received from author(s): September 16, 1999 